REGARDS

SUR L'ECONOMIE ALLEMANDE

BULLETIN ECONOMIQUE DU CIRAC
Regards sur l'économie allemande

Bulletin économique du CIRAC

$75 \mid 2006$

Varia

\title{
Budget : relance et compression du déficit
}

Isabelle Bourgeois

\section{CpenEdition}

Journals

Édition électronique

URL : http://journals.openedition.org/rea/844

DOI : $10.4000 /$ rea. 844

ISBN : 978-2-8218-0846-1

ISSN : 1965-0787

Éditeur

CIRAC

Édition imprimée

Date de publication : 1 mars 2006

Pagination : 37-38

ISSN : 1156-8992

Référence électronique

Isabelle Bourgeois, «Budget : relance et compression du déficit », Regards sur l'économie allemande [En ligne], 75 | mars 2006, document 1, mis en ligne le 19 juin 2008, consulté le 15 septembre 2020. URL : http://journals.openedition.org/rea/844

Ce document a été généré automatiquement le 15 septembre 2020

(C) CIRAC 


\section{Budget : relance et compression du déficit}

\section{Isabelle Bourgeois}

Le 22 février, le gouvernement fédéral a adopté un "budget de soutien à la conjoncture » pour 2006 afin de conquérir la marge de manœuvre nécessaire pour respecter dès 2007 les critères du Traité de Maastricht (déficit de 1,5\% du PIB en 2009) comme ceux de la Loi fondamentale dont l'art. 115 interdit que le montant de l'endettement soit supérieur aux dépenses d'investissement.

Planification budgétaire 2005-2009 du Bund

\begin{tabular}{|c|c|c|c|c|c|c|}
\hline en milliards $€$ & $\begin{array}{c}\text { Prévisionnel } \\
2005\end{array}$ & $\begin{array}{c}2005 \\
\text { exécuté }\end{array}$ & $\begin{array}{c}\text { Prévisionnel } \\
2006\end{array}$ & 2007 & 2008 & 2009 \\
\hline Dépenses & 254,3 & 259,8 & 261,7 & 269,1 & 272,5 & 275,3 \\
\hline $\begin{array}{l}\text { Var. / année } \\
\text { précédente }\end{array}$ & $+1,08$ & & $+2,91$ & $+2,83$ & $+1,26$ & $+1,03$ \\
\hline \multicolumn{7}{|l|}{ Recettes } \\
\hline Fiscales & 190,8 & 190,1 & 192,5 & 212,3 & 221,1 & 228,2 \\
\hline Divers & 41,5 & 38,5 & 30,9 & 34,8 & 30,1 & 27,1 \\
\hline Endettement net & 22,0 & 31,2 & 38,3 & 22,0 & 21,3 & 20,0 \\
\hline $\begin{array}{l}\text { Dépenses } \\
\text { d'investissement }\end{array}$ & 22,7 & 22,9 & 23,2 & 23,3 & 23,3 & 23,4 \\
\hline
\end{tabular}

Source : Ministère fédéral des Finances / Frankfurter Allgemeine Zeitung, 23-02-06. *) chiffres arrondis. 


\section{En négociation : un changement de régime pour la TVA des entreprises}

2 La plupart des 5 trains de mesures budgétaires figurant dans le contrat de coalition (voir REA 74/05) pour la durée de la législature et adoptées en février ne déploieront leurs effets qu'à partir de 2007. Les dépenses du Bund seront réduites de 32 milliards $€$, et les subventions, de 19 milliards $€$. Côté recettes, l'encours fiscal (dont la hausse de la TVA) s'accroîtra de 28 milliards $€$, à quoi s'ajoutent diverses recettes uniques telles que le fruit des privatisations ( 51 milliards $€$ ). Enfin, le changement de régime de la perception de la TVA apportera des recettes supplémentaires (non chiffrées) en limitant la fraude; le gouvernement allemand négocie actuellement son projet avec la Commission européenne : il consisterait à exempter de la TVA les transactions entre les entreprises dès lors que leur montant dépasse $5000 €$ (reverse charge); la TVA ne s'appliquera dans l'ensemble qu'aux transactions avec les particuliers.

Ventilation des dépenses du Bund par ministère

\begin{tabular}{|c|c|c|c|}
\hline en millions $€$ (chiffres arrondis) & $\begin{array}{l}\text { Prévis. } \\
2005\end{array}$ & $\begin{array}{l}\text { Prévis. } \\
2006\end{array}$ & $\begin{array}{c}2006 / 05(\text { en } \%) \\
*)\end{array}$ \\
\hline Présidence & 23,64 & 21,59 & $-8,7$ \\
\hline Bundestag & 550,92 & 556,93 & $+1,1$ \\
\hline Bundesrat & 19,95 & 18,89 & $-5,3$ \\
\hline Chancellerie & 1510,08 & 1621,83 & $+0,3$ \\
\hline Affaires étrangères & 2205,78 & 2292,59 & $+3,9$ \\
\hline Intérieur & 4126,64 & 4024,92 & $+0,1$ \\
\hline Justice & 338,59 & 339,07 & $+0,1$ \\
\hline Finances & 4041,77 & 4099,60 & $+1,4$ \\
\hline Economie et Technologies & 37974,67 & 5620,38 & $+1,3$ \\
\hline $\begin{array}{l}\text { Alimentation, Agriculture et Protection du } \\
\text { consommateur }\end{array}$ & 5106,96 & 5046,25 & $-1,2$ \\
\hline Travail et Affaires sociales & - & 119528,21 & $+4,0$ \\
\hline Transport, Construction et Urbanisme & 23255,51 & 23671,94 & $+1,8$ \\
\hline Défense & 23900,00 & 23880,00 & $-0,1$ \\
\hline Santé & 84409,88 & 4581,79 & $+60,3$ \\
\hline Environnement et Sécurité des réacteurs & 769,02 & 774,76 & $+0,7$ \\
\hline
\end{tabular}




\begin{tabular}{|l|c|c|c|}
\hline Famille, Seniors, Femmes et Enfants & 4571,69 & 4499,32 & $-1,5$ \\
\hline Tribunal constitutionnel fédéral & 17,63 & 16,60 & $-5,9$ \\
\hline Cour fédérale des Comptes & 86,67 & 85,22 & $-1,7$ \\
\hline Coopération économique et Développement & 3859,09 & 4159,63 & $+7,8$ \\
\hline Formation et Recherche & 8540,42 & 8003,10 & $+5,6$ \\
\hline Dette du Bund & 40431,84 & 39448,76 & $-2,4$ \\
\hline Retraites & 8821,01 & 8475,63 & $-3,9$ \\
\hline Administration générale & $-261,77$ & 933,00 & - \\
\hline Total & $\mathbf{2 5 4 3 0 0 , 0 0}$ & $\mathbf{2 6 1 7 0 0 , 0 0}$ & \\
\hline
\end{tabular}

Source : Ministère fédéral des Finances / Frankfurter Allgemeine Zeitung, 23-02-06. *) la reconfiguration des ministères est prise en compte.

\section{Travail et Affaires sociales : près de la moitié du budget fédéral}

3 Le plus gros poste budgétaire est celui du ministère du Travail et des Affaires sociales, qui représente $46 \%$ du total du budget fédéral. Il est en charge des mesures d'insertion gérées pour son compte par l'Agence fédérale pour l'emploi de Nuremberg, ainsi que des retraites. Ce dernier dossier est potentiellement conflictuel, puisque le ministère verse aux caisses légales de retraite un montant compensatoire pour équilibrer leur budget; il sert de variable d'ajustement pour éviter une hausse des cotisations ou une baisse des pensions. Le budget du ministère de la Santé (périmètre non comparable avec le ministère précédent) réduira de 4,2 milliards $€$ par an le montant compensatoire aux caisses d'assurance maladie légales; il sera définitivement supprimé en 2008. Or le gouvernement ayant décidé de ne pas procéder à une hausse des cotisations ni de réduire les prestations, une réforme de fond de l'assurance maladie est programmée pour la seconde moitié de 2006.

\section{INDEX}

Mots-clés : allocation, budget, conjoncture, déficit, finances publiques, fiscalité, impôt, politique économique, subvention, système social 